\title{
Smoking among adults with and without disabilities in the UK
}

\author{
Emerson, Eric \\ Professor of Disability Population Health, Centre for Disability Research and Policy, Faculty of Health \\ Sciences, University of Sydney, Sydney, Australia (PO Box 170, Lidcombe NSW 1825, Australia) \\ and \\ Emeritus Professor of Disability and Health Research, Centre for Disability Research, Lancaster \\ University, Lancaster, UK \\ eric.emerson@sydney.edu.au
}




\section{Abstract}

Background: The health risks of cigarette smoking are well established. As a result, reducing cigarette smoking is a key concern for public health agencies. Little is known about rates of smoking among adults with disabilities.

Methods: Secondary analysis of data collected in Waves 2 and 7 of Understanding Society, an annual household panel study.

Results: Age and gender adjusted odds ratios (AORs) of adults with disabilities smoking increased significantly from 1.41 (1.33-1.49) in 2010-12 to 1.57 (1.45-1.70) in 2015-17 ( $p=0.032$ ). AORs of adults with disabilities smoking 20 or more cigarettes a day increased non-significantly from 1.83 (1.66-2.02) in 2010-12 to 1.90 (1.65-2.20) in 2015-17. These changes were evident for both men and women and across age groups. Additionally adjusting these estimates to take account of between group differences in socioeconomic position significantly reduced the AORs for both smoking outcomes. Changes over time in AORs reflected a more rapid decline in smoking among participants without a disability.

Conclusions: Adults with disabilities are more likely than their peers to smoke. Public health agencies and practitioners may wish to consider what reasonable adjustments may need to be made to policies and interventions to ensure that they are effective for adults with disabilities. 


\section{Introduction}

The health risks of cigarette smoking are well established, with smoking substantially increasing the risk of death from lung and other cancers, heart disease, stroke, chronic respiratory disease and other conditions.[1, 2] As a result, cigarette smoking has long been regarded as a key concern for public health agencies.[3-6]

Policies aimed at reducing health inequalities, especially those based on individual behaviour change, need to specifically address the situations faced by population sub-groups that may be particularly vulnerable to exposure to established determinants of poorer health (e.g., .[5, 7-9] People with disabilities have been identified as one such group.[10,11] They are, for example, significantly more likely than their peers to be exposed to poverty, social exclusion and violence,[12-15] poor housing conditions, unemployment and non-standard working conditions.[16-19] They also have poorer health.[11] Relatively little is known about differential rates of key health behaviours, such smoking, between people with and without disabilities and how this may vary over time.

The majority of population based studies on smoking among people with disabilities have been undertaken in the U.S. These studies have consistently reported higher rates of smoking among US adults with disabilities when compared to their peers,[20-25] a pattern which has also been described in US samples of college students[26] and pregnant women.[27] Prevalence rate ratios in the US appear to be increasing over time due to a more rapid decrease in smoking among the non-disabled population. $[21,28]$

Studies from other countries have reported: (1) similar rates of smoking among Canadian adults with and without long-term health conditions;[29] (2) higher rates of smoking among Korean adults with disabilities when compared to non-disabled adults; [30] and (3) higher rates of smoking among British children and adolescents with intellectual disability [31, 32] and British adults with self-reported intellectual impairments.[33]

The aims of the present study were: (1) to estimate the prevalence of cigarette smoking among population-based samples of adults with and without disabilities living in the UK; (2) to examine whether differences in prevalence varied with age, gender, nature of functional impairment, socioeconomic position and over time. 


\section{Methods}

We undertook secondary analysis of data collected in Waves 2 and 7 of Understanding Society, an annual household panel study focusing on the social and economic circumstances, attitudes, behaviours and health of UK citizens (https://www.understandingsociety.ac.uk/). Data were downloaded from the UK Data Service (http://www.ukdataservice.ac.uk/). Full details of the surveys' development and methodology are available in a series of papers and reports, [34-37] key aspects of which are summarized below.

\section{Samples}

In the first wave of data collection (undertaken between January 2009 and December 2011), random sampling from the Postcode Address File in Great Britain and from the Land and Property Services Agency list of domestic properties in Northern Ireland identified 55,684 eligible households across the UK. Interviews were completed with 50,994 individuals aged 16 or older from 30,117 households, giving a household response rate of $54 \%$ and an individual response rate within participating households of 86\%.[37, 38] At Wave 2 (2010-12) full interviews were completed with 50,389 individuals aged 16 and over (the target population for our analyses).[39] At Wave 7 (2015-17) interviews were completed with 39,092 individuals aged 16 and over.[39] As the survey is a longitudinal household panel survey, new individuals enter the survey over time if: (a) they attain the age (16) at which they are interviewed as individuals; or (b) they become resident in the household. Individuals leave the survey if: (a) they no longer give consent to participate; (b) they cannot be traced; or (c) they move abroad. In addition, an immigrant and ethnic minority boost sample was introduced at Wave 6.[40]

\section{Procedures}

Data collection for variables used in the present paper was undertaken using face-to-face personal interviews in which the interviewer recorded responses on a laptop computer programmed to skip irrelevant questions.[34, 35]

\section{Measures}

\section{Disability or Long-Term Health Condition}

Disability/long-term health condition was ascertained by an affirmative response to a single question: 'Do you have any long-standing physical or mental impairment, illness or disability? By 'long-standing' I mean anything that has troubled you over a period of at least 12 months or that is likely to trouble you over a period of at least 12 months.' The overall prevalence of disability/long-term health condition in 
the targeted age group (16+) was $36 \%$ in both Waves. The prevalence of disability was strongly related to age, rising from approximately $17 \%$ among participants aged below 30 years to $62 \%$ among participants aged 70 or older.

\section{Functional Impairment}

Participants who reported having a disability/long-term health condition were asked 'Does this/Do these health problem(s) or disability(ies) mean that you have substantial difficulties with any of the following areas of your life?'. The response options (of which all that applied were coded) were: mobility (moving around at home and walking); lifting, carrying or moving objects; manual dexterity (using your hands to carry out everyday tasks); continence (bladder and bowel control); hearing (apart from using a standard hearing aid); sight (apart from wearing standard glasses); communication or speech problems; memory or ability to concentrate, learn or understand; recognising when you are in physical danger; physical coordination (e.g. balance); difficulties with own personal care (e.g. getting dressed, taking a bath or shower); other. For each of these we created binary variables; 1 designating disability with the specific functional impairment, 0 designating no disability.

\section{Smoking}

A brief questionnaire module addressing current smoking was administered in Waves 2 and 7. This contained two questions used in the current analyses: (1) 'Do you smoke cigarettes at all nowadays?' (2) 'Approximately how many cigarettes a day do you usually smoke, including those you roll yourself?'. From responses to these questions we derived two binary variables: (1) current smoker (vs. not); (2) currently smokes $20+$ cigarettes a day (vs. not a current smoker).

\section{Socioeconomic Position}

We derived four indicators of socio-economic position at each wave.

Income poverty

Household income and household composition were combined to calculate equivalised household income using the modified OECD equivalence scale. Income poverty was defined as the equivalised household income falling below $60 \%$ of the sample median, a measure of income poverty regularly used in the UK and internationally.[41]

\section{Consumer durables}

Informants were asked whether they had access to a list of 13 consumer durables (e.g., a colour television, a mobile phone). We derived a binary variable of low access to consumer durables with 0 
designating access to eight or more of the list of 13 consumer durables, 1 designating access to less than 8 of the list of 13 consumer durables.

\section{Self-assessed financial status}

Informants were asked 'How well would you say you yourself are managing financially these days? Would you say you are... 1 Living comfortably, 2 Doing alright, 3 Just about getting by, 4 Finding it quite difficult, 5 or finding it very difficult?'

\section{Housing Tenure}

Information was collected on housing tenure. From this we derived a binary variable where 0 designated home owned with or without mortgage and 1 designated all other tenure options (renting for approximately $99.5 \%$ of respondents who did not own their home).

\section{Ethical Approval}

Understanding Society is designed and conducted in accordance with the ESRC Research Ethics Framework and the ISER Code of Ethics. The University of Essex Ethics Committee approved Waves 1-7 of Understanding Society.

\section{Approach to Analysis}

All analyses were undertaken in IBM SPSS v24 using the complex samples module to address clustering in complex sample design and with appropriative cross sectional sample weights to take account of sample design, recruitment and attrition. As a result, all estimates can be considered as being representative of the UK population even though the sampling method involved oversampling of some specific ethnic groups and attrition over time was non-random.

We focused on Waves 2 and 7 as they were respectively the first wave in which smoking was assessed and the most recent wave in which smoking was assessed. First, we calculated crude prevalence and unadjusted odds ratios for adults with and without disabilities for the two measures of smoking at each Wave. All analyses were stratified by age group and gender.

Second, we used multivariate logistic regression to estimate odds ratios for participants with disabilities of smoking (participants without disabilities being the reference category). In Model 1 we calculated unadjusted estimates. In Model 2 we adjusted for between group differences in age, gender and ethnicity. In Model 3 we adjusted for between group differences age, gender, ethnicity and socioeconomic position. 
There was minimal missing data for the key exposure variable, disability $(0.0 \%$ at Wave $2,0.2 \%$ at Wave 7). The percentage of missing data for the outcome variables was $0.0 \%$ at Waves 2 and 7 for current smoker and $0.0 \%$ at Wave 2 and $0.2 \%$ at Wave 7 for smoking $20+$ a day. There were no missing data for gender or age. Item non-response missing data for income are imputed by the Institute for Social and Economic Research and deposited with the raw data in the UK Data Archive. Imputation methods used vary by type of variable and include linear regression, interval regression, logistic regression, ordered logistic regression, multinomial logistic regression, predictive mean matching and hot-deck imputation. Full details are given in the user guide.[36] Missing data for the covariates were: consumer durables (0.7\% at Wave $2,1.7 \%$ at Wave 7$)$, self-assessed financial status ( $0.1 \%$ at Wave $2,0.2 \%$ at Wave 7$)$, income poverty $(0.0 \%$ at Wave $2,0.7 \%$ at Wave 7$)$, housing tenure $(0.1 \%$ at Wave $2,0.8 \%$ at Wave 7$)$. Given the minimal amount of missing data complete case analysis was undertaken. Disability and smoking data were available for 17,715 participants with disability and 31,895 participants without disability at Wave 2, and 10,633 participants with disability and 19,237 participants without disability at Wave 7.

\section{Results}

At both waves participants with disability were more likely to be older (Wave 2: $43 \%$ vs. $20 \%$ aged 60 plus, OR=3.11(2.91-3.32)), women (Wave 2: 56\% vs. 53\%, OR=1.12(1.06-1.19)) and have lower socioeconomic position (Wave 2: income poverty $23 \%$ vs. $17 \%$, OR=1.42(1.31-1.53)). The associations between covariates and smoking status are presented in Table 1. At both waves significantly higher prevalence of smoking was associated with male gender, younger age and lower socioeconomic position.

[Insert Table 1]

Age and gender specific prevalence of for smoking is presented in Table 2. There are a number of noteworthy patterns in these results. First, for both men and women the ORs associated with smoking and heavy smoking (20 plus cigarettes a day) among participants with disability increased from Wave 2 (2010-12) to Wave 7 (2015-17) in most age groups. Second, for both men and women the ORs associated with smoking among participants with disability were greater for heavy smoking than for smoking at all. Third, among non-disabled participants men were more likely to smoke and smoke heavily than women. This association with gender was less consistent among participants with 
disabilities. Of particular note were the high ORs associated with smoking among women with disabilities in the under 30 group at both Waves of data collection.

In order to examine these changes over time in greater detail we calculated direct age-standardised prevalence rates (using the European Standard Population) separately for men and women with and without disabilities at the two points in time. For men with disabilities, the age-standardised prevalence rate of being a current smoker reduced from $26.9 \%$ (95\% Cl 25.5\%-28.4\%) at Wave 2 to $21.6 \%$ (20.2\%23.0\%) at Wave 7. For men without disabilities, the age-standardised prevalence rate of being a current smoker reduced from $21.4 \%$ (20.6\%-22.3\%) at Wave 2 to $16.0 \%$ (15.2\%-16.7\%) at Wave 7. The absolute difference in smoking prevalence increased from 5.3 percentage points at Wave 2 to 5.4 percentage points at Wave 7. Similarly, for women with disabilities, the age-standardised prevalence rate of being a current smoker reduced from $25.4 \%$ (24.1\%-26.6\%) at Wave 2 to $20.7 \%$ (19.5\%-22.0\%) at Wave 7 . For women without disabilities, the age-standardised prevalence rate of being a current smoker reduced from $18.7 \%$ (17.9\%-19.4\%) at Wave 2 to $13.5 \%$ (12.8\%-14.1\%) at Wave 7. The absolute difference in smoking prevalence increased from 4.7 percentage points at Wave 2 to 5.2 percentage points at Wave 7.

[Insert Table 2]

Table 3 presents the results of analyses estimating the ORs associated with smoking among participants with disability unadjusted, and adjusted for age and gender (Model 1) and age, gender and socioeconomic position (Model 2). Adjusting for between group differences in age and gender (Model 1) significantly increases the ORs associated with smoking and heavy smoking at both waves. For all comparisons and outcomes ORs were greater at Wave 7 than Wave 2. Additionally adjusting to take account of between group differences in socioeconomic position significantly reduces the ORs for both outcomes. The increase between Waves 2 and 7 in the age and gender adjusted ORs of adults with disabilities smoking was statistically significant $(Z=2.15, p=0.032)$. The increase in the adjusted OR of heavy smoking was not $(Z=0.43)$.

Finally we estimated uptake and cessation rates for smoking between Waves 2 and 7 for two cohorts of participants: (1) those who were disabled at both waves ( $n=7,087)$; and (2) those who were not disabled at either wave $(n=14,357)$. Uptake rates were low and did not vary between cohorts $(2.4 \%(2.0 \%-3.0 \%)$ vs. $3.0 \%(2.7 \%$ vs. $3.4 \%)$ ). Cessation rates were significantly greater for non-disabled participants ( $34.4 \%$ 
(32.3\%-36.6\%) vs. $27.2 \%$ (24.7\%-30.0\%)). ORs of participants with disabilities smoking at Wave 7 (adjusted for age, gender and smoking status at Wave 2) were 1.38 (1.20-1.60).

[Insert Table 3]

Table 4 presents the results of analyses estimating ORs associated with smoking among participants with disability and specific functional impairments at Wave 7 adjusted for age and gender (Model 1). All functional impairments were associated with significantly higher ORs of both smoking and heavy smoking. Similar patterns were apparent in Wave 2 data.

[Insert Table 4]

\section{Discussion}

\section{Main Findings of the Study}

The main results of this study are that: (1) the age and gender adjusted ORs associated with adults with disabilities being a current smoker increased significantly from 1.38 (1.29-1.48) in 2010-12 to 1.57 (1.451.70) in 2015-17; (2) the age and gender adjusted ORs associated with adults with disabilities smoking heavily increased from 1.75 (1.55-1.99) in 2010-12 to 1.90 (1.65-2.20) in 2015-17; (3) these changes were evident for both men and women and across age groups; (4) cessation rates were significantly lower for participants who were disabled at both waves when compared to participants who were not disabled at either wave; (5) additionally adjusting these estimates to take account of between group differences in socioeconomic position significantly reduced (but did not eliminate) the estimates for both smoking outcomes; (6) increased ORs associated with smoking were apparent across all functional impairments associated with disability.

\section{What is Already Known on this Topic}

Studies have consistently reported higher prevalence of smoking among US adults with disabilities when compared to their non-disabled peers.[20-24] Prevalence rate ratios in the US appear to be increasing over time due to a more rapid decrease in smoking among the non-disabled population.[21, 28] Population based studies from other countries are rare and have reported inconsistent results[29, 30]

\section{What this Study Adds}

These results add to the existing literature in two important ways. First, they indicate that in a contemporary nationally representative UK sample, adults with disabilities are significantly more likely 
than their age and gender matched non-disabled peers to smoke and to smoke heavily (20 or more cigarettes a day). While no conclusions regarding causality should be drawn from these data, the results clearly indicate that UK adults with disabilities are more likely than their peers to be exposed to a wellestablished determinant of poor health. Particularly concerning are: (1) the markedly higher comparative rates of smoking among younger adults, especially women with disabilities; and (2) the increase in comparative rates over time. As described above, the changes over time reflected a more rapid decline in the prevalence of smoking among participants without a disability. These results are consistent with previous research which has documented the extent to which public health policies based on behaviour change may be more successful among more affluent and educated sectors of the population and may consequently serve to increase inequalities in health.[6, 8, 9] Public health agencies and practitioners may wish to consider what reasonable adjustments may need to be made to cessation programmes and awareness campaigns to ensure that they are more effective for adults with disabilities. Additional research, including qualitative research, is required to better understand the mechanisms that underlie the higher prevalence of smoking among British adults with disabilities.

Second, the results indicate that adjustment for between-group differences in socioeconomic position significantly attenuate, but do not eliminate, the high ORs associated with smoking and smoking heavily among adults with disabilities. These results are consistent with the notion that the poorer health of people with disabilities may reflect the poorer living conditions in which people with disabilities grow up, live and work, as well as health risks biologically linked to the health conditions or impairments associated with disability.[5, 11]

\section{Limitations of this Study}

The main strength of the present study lies in its use of a large nationally representative sample of UK adults. The main weaknesses of the study are the reliance on self-report indicators of disability and smoking. While self-report measures of disability are commonly included in major health and social surveys, differences in procedure and wording can result in significant variation in the estimated prevalence of disability and the characteristics of individuals identified as disabled.[42-46] With regard to smoking status, the available evidence suggests that that self-report measures of smoking correspond reasonably well with smoking status assessed by biomarkers such as cotinine. $[47,48]$ However, no information is available to determine whether the degree of correspondence between self-report and biomarkers of smoking varies by disability status. 


\section{References}

1. World Health Organisation: Global Health Risks: Mortality and burden of disease attributable to selected major risks. In. Geneva: World Health Organisation; 2009.

2. World Health Organization: Global Report: Mortality Attributable to Tobacco. In. Geneva: World Health Organization; 2012.

3. World Health Organization: World Report on the Global Tobacco Epidemic 2017: Monitoring tobacco use and prevention policies. In. Geneva: World Health Organization; 2017.

4. World Health Organization Regional Office for Europe: Taking Stock: Tobacco control in the WHO European Region in 2017. In. Copenhagen: World Health Organization; 2017.

5. World Health Organization Regional Office for Europe: Report on social determinants and the health divide in the WHO European Region: Final Report (updated). In. Copenhagen: World Health Organization Regional Office for Europe; 2014.

6. Department of Health: Healthy Lives, Healthy People: A tobacco control plan for England. In. London: Department of Health; 2011.

7. World Health Organization: Rio Political Declaration on Social Determinants of Health (http://www.who.int/sdhconference/declaration/en/). In. Geneva: World Health Organization; 2011.

8. White M, Adams J, Heywood P: How and why do interventions that increase health overall widen inequalities within populations? In: Social Inequality and Public Health. edn. Edited by Babones SJ. Bristol: Policy Press; 2009: 65-82.

9. Okechukwu C, Davison K, Emmons K: Changing health behaviors in a social conext. In: Social Epidemiology (2nd Edition). edn. Edited by Berkman LF, Kawachi I, Glymour MM. New York Oxford University Press; 2014: 365-395.

10. Emerson E, Madden R, Graham H, Llewellyn G, Hatton C, Robertson J: The health of disabled people and the social determinants of health. Public Health 2011, 125:145-147. 
11. Emerson E, Vick B, Graham H, Hatton C, Llewellyn G, Madden R, Rechel B, Robertson J: Disablement and health In: Routledge Companion to Disability Studies. edn. Edited by Watson N, Thomas C, Roulstone A. London: Routledge; 2012.

12. Hughes K, Bellis MA, Jones L, Wood S, Bates G, Eckley L, McCoy E, Mikton C, Shakespeare T, Officer A: Prevalence and risk of violence against adults with disabilities: a systematic review and meta-analysis of observational studies. Lancet 2012, 379(9826):1621-1629.

13. Jones L, Bellis MA, Wood S, Hughes K, McCoy E, Eckley L, Bates G, Mikton C, Shakespeare T, Officer A: Prevalence and risk of violence against children with disabilities: a systematic review and meta-analysis of observational studies. Lancet 2012, 380(9845):899-907.

14. Emerson E, Hatton C: The socio-economic circumstances of families supporting a child at risk of disability in Britain in 2002 In. Lancaster: Institute for Health Research, Lancaster University; 2005.

15. Heslop P, Emerson E: Poverty and social exclusion and disabled people: a worsening picture. In: Poverty and Social Exclusion in the UK: Volume 1. edn. Edited by Dermott E, Main G. Bristol: Policy Prress; 2018.

16. Kavanagh AM, Aitken Z, Baker E, LaMontagne AD, Milner A, Bentley R: Housing tenure and affordability and mental health following disability acquisition in adulthood. Social Science \& Medicine 2016, 151:225-232.

17. Kavanagh AM, Aitken Z, Emerson E, Sahabandu S, Milner A, Bentley R, LaMontagne AD, Pirkis J, Studdert D: Inequalities in socio-economic characteristics and health and wellbeing of men with and without disabilities: a cross-sectional analysis of the baseline wave of the Australian Longitudinal Study on Male Health. BMC Public Health 2016, 16(Suppl 3):1042.

18. Milner A, Krnjacki L, Butterworth P, Kavanagh A, LaMontagne AD: Does disability status modify the association between psychosocial job quality and mental health? A longitudinal fixedeffects analysis. Social Science and Medicine 2015, 144:104-111. 
19. Milner A, LaMontagne AD, Aitken Z, Bentley R, Kavanagh AM: Employment status and mental health among persons with and without a disability: evidence from an Australian cohort study. Journal of Epidemiology and Community Health 2014, 68:1064-1071.

20. Havercamp SM, Scott HM: National health surveillance of adults with disabilities, adults with intellectual and developmental disabilities, and adults with no disabilities. Disability \& Health Journal 2015, 8:165-172.

21. Glazier RE, Kling RN: Recent trends in substance abuse among persons with disabilities compared to that of persons without disabilities. Disability \& Health Journal 2013, 6:107-115.

22. Froehlich-Grobe K, Jones D, Businelle MS, Kendzor DE, Balasubramanian BA: Impact of disability and chronic conditions on health. Disability \& Health Journal 2016, 9:600-608.

23. Hall AG, Schumacher JR, Cannell MB, Berry JB, Schiaffino M, Park S: Tobacco use in Florida: Comparisons between adults living with and without disabilities. Disability \& Health Journal 2013, 6:213-219.

24. Courtney-Long EA, Stevens AC, Caraballo R, Ramon I, Armour BS: Disparities in current cigarette smoking prevalence by type of disability, 2009-2011. Public Health Reports 2014, 129:252-260.

25. Armour BS, Campbell VA, Crews JE, Malarcher A, Maurice E, Richard RA: State-level prevalence of cigarette smoking and treatment advice, by disability status, United States, 2004. Preventing Chronic Disease 2007, 4:1-11.

26. Jarrett T, Pignataro RM: Cigarette smoking among college students with disabilities: National College Health Assessment II, Fall 2008-Spring 2009. Disability \& Health Journal 2013, 6:204212.

27. Mitra M, Lu E, Diop H: Smoking among pregnant women with disabilities. Women's Health Issues 2012, 22:e233-e239.

28. Becker $\mathrm{H}$, Brown A: Disparities in smoking behaviors among those with and without disabilities from 2001 to 2005. Public Health Nursing 2008, 25:526-535. 
29. Schmitz N, Kruse J, Kugler J: Smoking and its association with disability in chronic conditions: Results from the Canadian Community and Health Survey 2.1. Nicotine \& Tobacco Research 2007, 9:959-964.

30. Lee J, Park J, Kim H, Shin H: Smoking behaviors among people with disabilities in Korea. Disability and Health Journal 2014, 7:236-241.

31. Emerson E, Turnbull L: Self-reported smoking and alcohol use by adolescents with and without intellectual disabilities. Journal of Intellectual Disabilities 2005, 9:58-69.

32. Emerson E, Hatton C, Baines S, Robertson J: Exposure to second hand tobacco smoke and smoking at age 11 among British children with and without intellectual disability (doi: 10.1111/jir.12247). Journal of Intellectual Disability Research 2016, 60:274-281.

33. Robertson J, Emerson E, Baines S, Hatton C: Obesity and health behaviours of British adults with self-reported intellectual impairments: cross sectional survey. BMC Public Health 2014, 14(1):219.

34. Boreham R: UKHLS: Wave 2 Technical Report. In. London: NatCen; 2012.

35. Carpenter H: UK Household Longitudinal Study: Wave 7 technical report. In. London: Kantar Public; 2017.

36. Knies G (ed.): Understanding Society: The UK Household Longitudinal Study Waves 1-7, User Manual. Colchester, UK: University of Essex; 2017.

37. Buck N, McFall SL: Understanding Society: design overview. Longitudinal and Life Course Studies 2012, 3:5-17.

38. McFall SL: Understanding Society -UK Household Longitudinal Study: Wave 1-2, 2009-2011, User Manual. In. Colchester: University of Essex; 2012.

39. Scott A, Jessop C: UK Household Longitudinal Study (UKHLS) Wave 3: Technical Report. In. London, UK: NatCen; 2013. 
40. Lynn P, Nandi A, Parutis V, Platt L: Design and implementation of a high quality probability sample of immigrants and ethnic minorities: Lessons learnt. In: Understanding Society Working Paper Series No 2017-11. Colchester: University of Essex; 2017.

41. Gordon D: Measuring poverty in the UK. In: Poverty and Social Exclusion in the UK: Volume 1. edn. Edited by Dermott E, Main G. Bristol: Policy Press; 2018: 17-40.

42. Mont D: Measuring Disability Prevalence. In. Washington, DC, USA: The World Bank; 2007.

43. Madans JH, Loeb ME, Altman BM: Measuring disability and monitoring the UN convention on the rights of persons with disabilities: The work of the Washington group on disability statistics. BMC Public Health 2011, 11(Suppl 4):S4.

44. Madans JH, Mont D, Loeb M: Comments on Sabariego et al. Measuring Disability: Comparing the Impact of Two Data Collection Approaches on Disability Rates. International Journal of Environmental Research and Public Health 2016, 13:65.

45. Sabariego C, Oberhauser C, Posarac A, Bickenbach J, Kostanjsek N, Chatterji S, Officer A, Coenen M, Chhan L, Cieza A: Measuring disability: Comparing the impact of two data collection approaches on disability rates. International Journal of Environmental Research and Public Health 2015, 12:10329-10351.

46. Sabariego C, Oberhauser C, Posarac A, Bickenbach J, Kostanjsek N, Chatterji S, Officer A, Coenen M, Chhan L, Cieza A: Response to Madans et al. Comments on Sabariego et al. Measuring Disability: Comparing the Impact of Two Data Collection Approaches on Disability Rates. International Journal of Environmental Research and Public Health 2016, 13:66.

47. Gorber SC, eld-Hurwitz SS, Hardt J, Levasseur G, Tremblay M: The accuracy of self-reported smoking: A systematic review of the relationship between self-reported and cotinine assessed smoking status. Nicotine \& Tobacco Research 2009, 11:12-24.

48. Wong SL, Shields M, Leatherdale S, Malaison E, Hammond D: Assessment of validity of selfreported smoking status. Health Reports 2012, 26(1):1-7. 


\begin{tabular}{|c|c|c|c|c|}
\hline \multicolumn{5}{|l|}{ Current smoker } \\
\hline & W2 \% & W2 OR & W7 \% & W7 OR \\
\hline Men & $23.2 \%(22.5 \%-23.9 \%)$ & \multirow[t]{2}{*}{$0.86(0.82-0.90)$} & $17.5 \%$ (16.7\%-18.3\%) & \multirow[t]{2}{*}{$0.86(0.81-0.92)$} \\
\hline Women & $20.5 \%(19.9 \%-21.1 \%)$ & & $15.5 \%(14.8 \%-16.2 \%)$ & \\
\hline Age $<60$ & $25.5 \%(24.9 \%-26.2 \%)$ & \multirow[t]{2}{*}{$0.41(0.39-0.44)$} & $19.1 \%$ (18.3\%-19.9\%) & \multirow[t]{2}{*}{$0.51(0.47-0.56)$} \\
\hline Age $>=60$ & $12.4 \%(11.8 \%-13.0 \%)$ & & $10.8 \%(10.1 \%-11.5 \%)$ & \\
\hline Income poverty & $28.9 \%(27.6 \%-30.1 \%)$ & \multirow[t]{2}{*}{$1.60(1.49-1.71)$} & $23.8 \%(22.2 \%-25.6 \%)$ & \multirow[t]{2}{*}{$1.74(1.57-1.93)$} \\
\hline Not income poverty & $20.2 \%(10.7 \%-20.8 \%)$ & & $15.2 \%(14.6 \%-15.9 \%)$ & \\
\hline Low consumer durables & $27.0 \%(25.4 \%-28.6 \%)$ & \multirow[t]{2}{*}{$1.38(1.27-1.50)$} & $25.5 \%$ (23.4\%-27.6\%) & \multirow[t]{2}{*}{$1.88(1.67-2.12)$} \\
\hline Not low consumer durables & $21.1 \%(20.6 \%-21.7 \%)$ & & $15.4 \%(14.8 \%-16.0 \%)$ & \\
\hline Rented accommodation & $36.8 \%$ (35.7\%-37.8\%) & \multirow[t]{2}{*}{$3.23(3.04-3.43)$} & $30.7 \%$ (29.4\%-32.1\%) & \multirow[t]{2}{*}{$3.93(3.61-4.27)$} \\
\hline Home owners & $15.2 \%(14.7 \%-15.8 \%)$ & & $10.2 \%(9.7 \%-10.7 \%)$ & \\
\hline $\begin{array}{r}\text { Self-assessed financial situation 'difficult' or 'very } \\
\text { difficult' }\end{array}$ & $40.1 \%(38.6 \%-41.7 \%)$ & \multirow[t]{2}{*}{$2.76(2.57-3.00)$} & $38.1 \%(35.1 \%-41.2 \%)$ & \multirow[t]{2}{*}{$3.45(3.02-3.95)$} \\
\hline $\begin{array}{r}\text { Self-assessed financial situation not 'difficult' or } \\
\text { 'very difficult' }\end{array}$ & $19.5 \%(19.0 \%-20.1 \%)$ & & $15.1 \%(14.6 \%-15.7 \%)$ & \\
\hline \multicolumn{5}{|l|}{ Current smoker 20 plus a day } \\
\hline & W2 \% & W2 OR & W7 \% & W7 OR \\
\hline Men & $6.8 \%(6.4 \%-7.2 \%)$ & \multirow{2}{*}{$\begin{array}{l}0.64 \\
(0.58-0.69)\end{array}$} & $5.0 \%(4.5 \%-5.4 \%)$ & \multirow[t]{2}{*}{$0.62(0.55-0.71)$} \\
\hline Women & $4.4 \%(4.2 \%-4.7 \%)$ & & $3.1 \%(2.8 \%-3.5 \%)$ & \\
\hline Age $<60$ & $6.3 \%(6.0 \%-6.6 \%)$ & \multirow{2}{*}{$\begin{array}{l}0.56 \\
(0.50-0.63)\end{array}$} & $4.4 \%(4.0 \%-4.8 \%)$ & \multirow[t]{2}{*}{$0.73(0.63-0.85)$} \\
\hline Age $>=60$ & $3.6 \%(3.3 \%-4.0 \%)$ & & $3.2 \%(2.9 \%-3.6 \%)$ & \\
\hline Income poverty & $7.9 \%(7.2 \%-8.6 \%)$ & $1.62(1.45-1.81)$ & $6.1 \%(5.2 \%-7.1 \%)$ & $1.68(1.40-2.02)$ \\
\hline
\end{tabular}




\begin{tabular}{|c|c|c|c|c|}
\hline Not income poverty & $5.0 \%(4.8 \%-5.3 \%)$ & & $3.7 \%(3.4 \%-4.0 \%)$ & \\
\hline Low consumer durables & $7.6 \%(6.7 \%-8.6 \%)$ & \multirow[t]{2}{*}{$1.47(1.28-1.69)$} & $6.4 \%$ (5.3\%-7.6\%) & \multirow[t]{2}{*}{$1.73(1.41-2.13)$} \\
\hline Not low consumer durables & $5.3 \%(5.0 \%-5.6 \%)$ & & $3.8 \%(3.5 \%-4.1 \%)$ & \\
\hline Rented accommodation & $10.3 \%(9.7 \%-11.0 \%)$ & \multirow[t]{2}{*}{$3.21(2.92-3.53)$} & $8.4 \%$ (7.7\%-9.2\%) & \multirow[t]{2}{*}{$4.30(3.73-4.94)$} \\
\hline Home owners & $3.5 \%(3.2 \%-3.7 \%)$ & & $2.1 \%(1.9 \%-2.3 \%)$ & \\
\hline $\begin{array}{r}\text { Self assessed financial situation 'difficult' or 'very } \\
\text { difficult' }\end{array}$ & $12.1 \%(11.1 \%-13.2 \%)$ & \multirow[t]{2}{*}{$2.76(2.49-3.06)$} & $12.4 \%(10.4 \%-14.6 \%)$ & \multirow[t]{2}{*}{$3.86(3.15-4.73)$} \\
\hline $\begin{array}{r}\text { Self assessed financial situation not 'difficult' or } \\
\text { 'very difficult' }\end{array}$ & $4.7 \%(4.5 \%-5.0 \%)$ & & $3.5 \%(3.3 \%-3.8 \%)$ & \\
\hline
\end{tabular}




\begin{tabular}{|c|c|c|c|c|c|c|}
\hline Age & & Men & & & Women & \\
\hline $\begin{array}{l}\text { W2: } \\
\text { Current } \\
\text { smoker }\end{array}$ & Disabled & Non-Disabled & OR & Disabled & Non-Disabled & OR \\
\hline$<30$ & $35.2 \%(31.0 \%-39.5 \%)$ & $27.7 \%(25.9 \%-29.6 \%)$ & $1.42(1.15-1.74)$ & $33.0 \%$ (29.5\%-36.6\%) & $25.0 \%$ (23.4\%-26.6\%) & $1.48(1.24-1.77)$ \\
\hline $30-39$ & $39.1 \%(34.8 \%-43.7 \%)$ & $29.3 \%(27.3 \%-31.5 \%)$ & $1.55(1.26-1.91)$ & $34.4 \%(31.1 \%-37.9 \%)$ & $21.2 \%(19.7 \%-22.9 \%)$ & $1.94(1.63-2.32)$ \\
\hline $60-69$ & $16.9 \%(15.0 \%-18.9 \%)$ & $17.2 \%(15.2 \%-19.4 \%)$ & $0.97(0.80-1.19)$ & $16.6 \%(15.0 \%-18.5 \%)$ & $14.6 \%(12.9 \%-16.5 \%)$ & $1.16(0.97-1.41)$ \\
\hline $70+$ & $8.8 \%(7.3 \%-10.5 \%)$ & $9.4 \%(7.6 \%-11.6 \%)$ & $0.93(0.69-1.25)$ & $8.6 \%(7.4 \%-10.0 \%)$ & $8.7 \%(7.3 \%-10.4 \%)$ & $0.99(0.76-1.27)$ \\
\hline \multicolumn{7}{|c|}{ W7: Current smoker } \\
\hline$<30$ & $23.6 \%(18.7 \%-29.4 \%)$ & $20.4 \%(18.3 \%-22.7 \%)$ & $1.21(0.87-1.67)$ & $24.3 \%$ (19.9\%-29.4\%) & $17.2 \%(15.4 \%-19.3 \%)$ & $1.54(1.16-2.06)$ \\
\hline $30-39$ & $29.5 \%(24.0 \%-35.8 \%)$ & $21.3 \%(18.8 \%-24.0 \%)$ & $1.55(1.12-2.14)$ & $28.4 \%(24.2 \%-33.0 \%)$ & $15.7 \%(13.8 \%-17.8 \%)$ & $2.13(1.64-2.75)$ \\
\hline $40-49$ & $27.8 \%(23.8 \%-32.2 \%)$ & $15.9 \%(14.1 \%-18.0 \%)$ & $2.03(1.57-2.62)$ & $23.5 \%(20.6 \%-26.8 \%)$ & $14.8 \%(13.1 \%-16.7 \%)$ & $1.77(1.42-2.21)$ \\
\hline \multicolumn{7}{|c|}{ W2: Currently smoking 20 plus a day } \\
\hline$<30$ & $9.5 \%(7.2 \%-12.5 \%)$ & $3.9 \%(3.2 \%-4.8 \%)$ & $2.57(1.80-3.66)$ & $6.7 \%(5.1 \%-8.8 \%)$ & $2.2 \%(1.7 \%-2.8 \%)$ & $3.24(2.20-4.78)$ \\
\hline $30-39$ & $12.3 \%$ (9.8\%-15.5\%) & $6.1 \%(5.1 \%-7.2 \%)$ & $2.16(1.57-2.98)$ & $8.7 \%(6.8 \%-11.1 \%)$ & $3.4 \%(2.8 \%-4.2 \%)$ & $2.68(1.92-3.75)$ \\
\hline $40-49$ & $13.9 \%(11.8 \%-16.4 \%)$ & $8.4 \%(7.2 \%-9.7 \%)$ & $1.77(1.37-2.29)$ & $10.5 \%$ (8.9\%-12.4\%) & $5.1 \%(4.3 \%-5.9 \%)$ & $2.20(1.72-2.82)$ \\
\hline $50-59$ & $11.7 \%(10.0 \%-13.7 \%)$ & $8.6 \%(7.3 \%-10.1 \%)$ & $1.41(1.09-1.81)$ & $7.9 \%$ (6.6\%-9.4\%) & $5.0 \%(4.1 \%-6.0 \%)$ & $1.63(1.25-2.14)$ \\
\hline $60-69$ & $6.5 \%$ (5.4\%-7.9\%) & $6.5 \%(5.2 \%-8.1 \%)$ & $1.00(0.73-1.37)$ & $5.5 \%(4.6 \%-6.7 \%)$ & $3.4 \%(2.6 \%-4.5 \%)$ & $1.65(1.17-2.33)$ \\
\hline $70+$ & $2.4 \%(1.7 \%-3.3 \%)$ & $2.4 \%(1.5 \%-3.6 \%)$ & $1.00(0.57-1.76)$ & $1.9 \%(1.4 \%-2.7 \%)$ & $1.1 \%(0.5 \%-2.5 \%)$ & $1.79(0.71-4.48)$ \\
\hline \multicolumn{7}{|c|}{ W7: Currently smoking 20 plus a day } \\
\hline $7<30$ & $3.9 \%(2.1 \%-7.2 \%)$ & $3.0 \%(2.2 \%-4.1 \%)$ & $1.32(0.64-2.72)$ & $4.5 \%(2.7 \%-7.2 \%)$ & $1.2 \%(0.8 \%-1.9 \%)$ & $3.81(1.90-7.62)$ \\
\hline $30-39$ & $8.0 \%(5.2 \%-12.1 \%)$ & $4.2 \%(3.1 \%-5.6 \%)$ & $1.98(1.15-3.40)$ & $5.4 \%(3.6 \%-8.1 \%)$ & 2.7\% (1.9\%-3.7\%) & $2.10(1.21-3.63)$ \\
\hline $40-49$ & $9.9 \%(7.4 \%-13.3 \%)$ & $4.8 \%(3.8 \%-6.1 \%)$ & $2.20(1.45-3.32)$ & 7.1\% (5.5\%-9.2\%) & $3.0 \%(2.2 \%-3.9 \%)$ & $2.50(1.67-3.75)$ \\
\hline $50-59$ & $10.4 \%$ (8.4\%-12.9\%) & $6.0 \%$ (4.8\%-7.5\%) & $1.83(1.30-2.58)$ & $7.5 \%$ (5.9\%-9.5\%) & $2.8 \%(2.1 \%-3.8 \%)$ & $2.79(1.90-4.10)$ \\
\hline
\end{tabular}


Notes: Reference group for all odds ratios are participants without disabilities. Denominator for 'currently smoking $20+$ ' is all current smokers and non-smokers.

W $=$ Wave, $O R=$ odds ratio with $95 \%$ confidence intervals 


\begin{tabular}{|c|c|c|c|}
\hline Outcome \& Wave & Unadjusted & $\begin{array}{l}\text { Model } 1 \text { (adjusted for } \\
\text { age and gender) }\end{array}$ & $\begin{array}{l}\text { Model } 2 \text { (adjusted for } \\
\text { age, gender and } \\
\text { socioeconomic position) }\end{array}$ \\
\hline $\begin{array}{l}\text { Wave 2: Current } \\
\text { smoker }\end{array}$ & $1.01(0.95-1.06)$ & $1.41(1.33-1.49)$ & $1.10(1.04-1.17)$ \\
\hline $\begin{array}{l}\text { Wave 7: Current } \\
\text { smoker }\end{array}$ & $1.20(1.11-1.29)$ & $1.57(1.45-1.70)$ & $1.15(1.06-1.25)$ \\
\hline $\begin{array}{l}\text { Wave 2: Currently } \\
\text { smoking } 20+\end{array}$ & $1.58(1.44-1.72)$ & $1.83(1.66-2.02)$ & $1.37(1.23-1.52)$ \\
\hline $\begin{array}{l}\text { Wave 7: Currently } \\
\text { smoking } 20+\end{array}$ & $1.72(1.50-1.97)$ & $1.90(1.65-2.20)$ & $1.34(1.16-1.56)$ \\
\hline \multicolumn{4}{|c|}{$\begin{array}{l}\text { Note: reference group = participants without disabilities, denominator for 'currently smoking } 20+\text { ' is all } \\
\text { current smokers and non-smokers, age entered as categorical variable }(<30,30-39,40-49,50-59,60-69 \text {, } \\
70+) \text {, self-assessed financial situation entered as categorical variable (living comfortably, doing alright, } \\
\text { just about getting by, finding it quite difficult, finding it very difficult), all other covariates entered as } \\
\text { binary variables. }\end{array}$} \\
\hline
\end{tabular}




\begin{tabular}{|c|c|c|}
\hline & Current Smoker & Currently Smoking 20+ \\
\hline Mobility & $2.21(1.96-2.49)$ & $2.81(2.32-3.40)$ \\
\hline Lifting/carrying & $2.15(1.92-2.41)$ & $2.67(2.20-3.25)$ \\
\hline Manual dexterity & $2.25(1.93-2.64)$ & $2.91(2.27-3.72)$ \\
\hline Continence & $1.98(1.62-2.42)$ & $2.72(2.00-3.69)$ \\
\hline Hearing & $1.76(1.40-2.25)$ & $2.21(1.49-3.28)$ \\
\hline Sight & $1.75(1.39-2.19)$ & $3.05(2.21-4.22)$ \\
\hline Communication or speech & $2.16(1.62-2.87)$ & $3.26(2.18-4.86)$ \\
\hline Memory, concentration, learning, understanding & $2.29(1.95-2.68)$ & $3.39(2.68-4.29)$ \\
\hline Recognising physical danger & $3.03(2.15-4.29)$ & $5.05(3.10-8.23)$ \\
\hline Physical co-ordination & $2.06(1.74-2.44)$ & $2.82(2.15-3.70)$ \\
\hline Difficulties with personal care & $2.35(1.96-2.80)$ & $3.46(2.68-4.46)-$ \\
\hline Other & $2.05(1.79-2.35)$ & $2.63(2.07-3.36)$ \\
\hline \multicolumn{3}{|c|}{$\begin{array}{l}\text { Note: reference group = participants without disabilities. Denominator for 'currently smoking } 20+\text { ' is all } \\
\text { current smokers and non-smokers. Risk estimate adjusted for age and gender. Age entered as } \\
\text { categorical variable }(<30,30-39,40-49,50-59,60-69,70+) \text {. }\end{array}$} \\
\hline
\end{tabular}

